\title{
The epidemiology of tuberculosis in health care workers in South Africa: a systematic review
}

Liesl Grobler ${ }^{1 *}$, Shaheen Mehtar ${ }^{2}$, Keertan Dheda ${ }^{3}$, Shahieda Adams ${ }^{4}$, Sanni Babatunde ${ }^{5}$, Martie van der Walt ${ }^{6}$ and Muhammad Osman ${ }^{7}$

\begin{abstract}
Background: In South Africa, workplace acquired tuberculosis (TB) is a significant occupational problem among health care workers. In order to manage the problem effectively it is important to know the burden of TB in health care workers. This systematic review describes the epidemiology of TB in South African health care workers.

Methods: A comprehensive search of electronic databases [MEDLINE, EMBASE, Web of Science (Social Sciences Citation Index/Science Citation Index), Cochrane Library (including CENTRAL register of Controlled Trials), CINAHL and WHO International Clinical Trials Registry Platform (ICTRP)] was conducted up to April 2015 for studies reporting on any aspect of TB epidemiology in health care workers in South Africa.

Results: Of the 16 studies included in the review, ten studies reported on incidence of active TB disease in health care workers, two report on the prevalence of active TB disease, two report on the incidence of latent TB infection, three report on the prevalence of latent TB infection and four studies report on the number of TB cases in health care workers in various health care facilities in South Africa. Five studies provide information on risk factors for TB in health care workers. All of the included studies were conducted in publicly funded health care facilities;

predominately located in KwaZulu-Natal and Western Cape provinces. The majority of the studies reflect a higher incidence and prevalence of active TB disease in health care workers, including drug-resistant TB, compared to the surrounding community or general population.

Conclusions: There is relatively little research on the epidemiology of TB in health care workers in South Africa, despite the importance of the issue. To determine the true extent of the TB epidemic in health care workers, regular screening for TB disease should be conducted on all health care workers in all health care facilities, but future research is required to investigate the optimal approach to TB screening in health care workers in South Africa. The evidence base shows a high burden of both active and latent TB in health care workers in South Africa necessitating an urgent need to improve existing TB infection, prevention and control measures in South African health care facilities.
\end{abstract}

Keywords: Tuberculosis, Health care workers, Health personnel, Sub-Saharan Africa

\footnotetext{
* Correspondence: liesl.nicol@gmail.com

${ }^{1}$ Center for Evidence-based Health Care, Stellenbosch University, Cape Town,

South Africa

Full list of author information is available at the end of the article
} 


\section{Background}

Health care workers have an increased risk of acquiring tuberculosis (TB) as they are exposed to $\mathrm{TB}$ in their community as well as at their place of work [1-3]. In South Africa, workplace acquired TB is an important occupational disease among health care workers. According to the 2006 compensation fund claims, tuberculosis in health care workers, whilst generally underreported, is the third most commonly reported occupational disease in South Africa [4]. A review of the data submitted to the Compensation Commissioner by health care workers regarding hospital acquired infections from January 2007 to December 2009 in Limpopo province (i.e. one of the nine administrative divisions within the country) found that TB was the most common hospital acquired infection, with $47(83.9 \%)$ of the 56 reported cases of infectious diseases being TB cases [5].

Furthermore, the Human Immunodeficiency Virus (HIV) epidemic has impacted greatly on TB in South African health care workers. The HIV epidemic has increased the patient burden with $\mathrm{TB}$ co-infection in health care facilities, particularly at the primary care level. The increased number of sick patients with HIVrelated TB has increased health care workers' exposure to occupationally acquired diseases such as TB. Additionally, 11-20\% of South African health care workers are themselves, HIV-positive [6-8]. These HIV-infected health care workers have an increased risk for acquiring $\mathrm{TB}$ as well as for progressing from latent $\mathrm{TB}$ to active clinical disease [6].

Despite international policy recommendations [9] and national legislative provisions to address workplace acquired TB, generally South African health care facilities do not have adequate or appropriate infection prevention and control measures in place to protect their employees [10] (Dwadwa et al: Health worker access to HIV/TB prevention, treatment and care services in Africa: situational analysis and mapping of routine and current best practices, unpublished). The poorly enforced TB infection prevention and control policies (including administrative, engineering and personal protective equipment measures), the over-crowded health care facilities with insufficient ventilation to allow for appropriate environmental infection control and the high levels of undiagnosed, infectious TB patients, all contribute to health care workers' increased risk of exposure to TB in South African health care facilities.

The success of any TB Control Programme is dependent on health care workers' knowledge and application of appropriate policies and practices. In 2010 there were only 3.97 medical practitioner per 10000 population and 18.97 professional nurses per 10000 population in South Africa [11], reflecting the scarcity of health care workers in an overburdened health care system. TB infection amongst health care workers results in absenteeism and sometimes death or disability of health care workers, further weakening the already overburdened health care system.

The first step towards managing workplace acquired TB in South African health care workers is to determine the true burden of TB in this population. This systematic review aims to collate all research conducted in South Africa reporting on any aspect of epidemiology of TB in health care workers in South Africa.

\section{Methods}

This systematic review is part of a larger project aimed at identifying all scientific evidence on the epidemiology of, and programmatic response to, TB in South African health care workers (http://www.cebhc.co.za/researchkey-outputs/research-evisat/). The larger project collated information on TB epidemiology, TB infection, prevention and control and TB prevention, treatment and care among health care workers in South Africa. Only the results of the epidemiology of TB in health care workers will be presented here.

\section{Criteria for studies for inclusion in this review}

Based on previously published definitions, the term "health care worker" was defined as "all people engaged in actions whose primary intent is to enhance health" and included, but was not restricted to, physicians, nurses, allied health personnel, health educators, social workers, midwives, community health workers, laboratory personnel, pharmacists, radiographers, volunteers, orderlies, and health-facility administrators $[2,12]$. All studies reporting on any aspect of TB epidemiology in health care workers in South Africa were presented in this review.

\section{Search methods for identification of studies}

A comprehensive search strategy (see Table 1), without any date or language restrictions, was used to search the following databases:

- MEDLINE (1966 to April 2015)

- EMBASE (1947 to April 2015)

- WEB OF SCIENCE (Social Sciences Citation index/ Science Citation Index-1970 to April 2015)

- Cochrane Library (up to Issue 5 2013)-including CENTRAL register of Controlled Trials

- CINAHL (1981 to April 2015)

- WHO International Clinical Trials Registry Platform (ICTRP) up to April 2015

To identify additional research we contacted experts (for example, researchers, health care workers, South African Department of Health employees) working in 
Table 1 Detailed search strategy

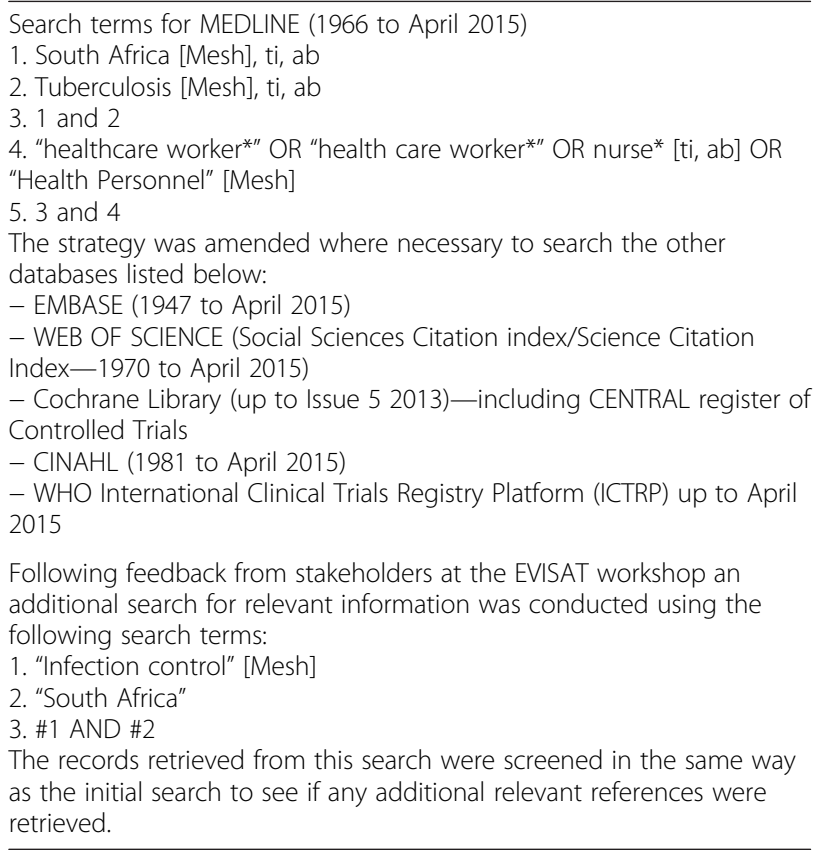

the field of TB in South Africa and screened the reference lists of eligible studies and review articles.

\section{Data collection and analysis}

Three reviewers independently screened the results of the searches (Liesl Nicol, Shaheen Mehtar and Keertan Dheda) and extracted data (Liesl Nicol, Muhammad Osman and Lydia Mudzikati) from eligible studies using a standardised data extraction form. Any disagreements regarding study eligibility or data extraction were resolved by discussion among the review team. The degree of selection bias, detection/information bias and confounding was determined for each included study using a validated risk of bias tool [13]. We planned to summarise the incidence data on TB in health care workers. However, after extracting the data from the eligible studies we noted that only some of the studies reported the $95 \%$ confidence interval or standard deviation around the mean incidence or prevalence values. After consultation with a statistician it was agreed that the high level of heterogeneity between the incidence values would make summation of the data meaningless. Therefore, we decided to present the data in a horizontal bar chart to graphically reflect the incidence of active TB disease in health care workers compared to the general population or surrounding community.

\section{Results}

\section{Search results}

The electronic search yielded a total of 668 references and searching other resources (for example: screening references of included studies, contacting experts in the field) yielded three additional studies (Fig. 1). A total of 587 references were excluded after the initial screening as the references either did not pertain to health care workers or the studies were not conducted in South Africa. We obtained the full text articles of 85 references, 48 of which were eligible for inclusion in the larger review looking at the epidemiology of and programmatic response to TB in South African health care workers. The reasons for excluding the remaining 37 references are outlined in Additional file 1: Table S1. The data from studies reporting on TB infection prevention and control, TB occupational health and safety, and care of health care workers with TB will be summarised in a future paper.

\section{Description of included studies}

We identified 16 studies reporting on various aspects of TB epidemiology in health care workers in South Africa. The detailed characteristics and findings of these studies are presented in Table 2 .

\section{Study setting and location}

All of the included studies were conducted in publicly funded (government-funded), as opposed to privately funded, health care facilities in South Africa. Studies were conducted in health care facilities located in KwaZuluNatal and the Western Cape, two of the nine South African provinces (i.e. administrative divisions within the country). We did not find any studies reporting on TB epidemiology in health care workers in the Eastern Cape, Free State, the Northern Cape and the North West province. The included studies provide information on TB epidemiology in health care workers in primary, secondary and tertiary level health care facilities. One study was conducted from a mobile testing unit in a community-based, as opposed to facility-based, setting [6].

\section{Study design and risk of bias}

Eight retrospective cohort studies, six cross-sectional studies and two prospective cohort study provided information on the epidemiology of TB in health care workers. Table 3 provides a summary of the risk for selection bias, detection/information bias and confounding present in each of the included studies. The risk of selection bias and detection/information bias was judged to be low in the retrospective cohort studies as these studies extracted data from hospital records or databases using data extraction forms. However, it is well known that there is underreporting of TB cases among health care workers, which may introduce detection/information bias and affect the external validity of the studies. Confounding was judged to be unclear in most of the studies as it is often unclear if the TB was acquired in the community or in the work 


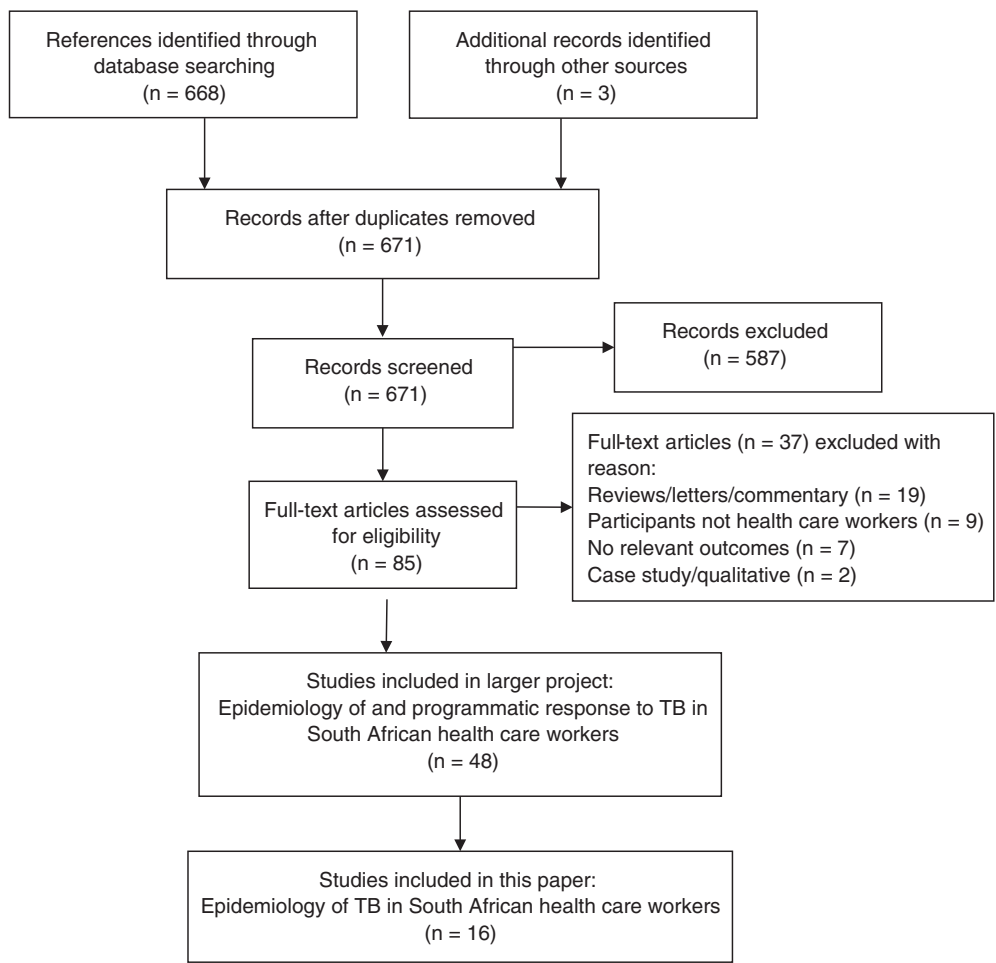

Fig. 1 Flow diagram showing selection of studies

place because of the high background incidence and prevalence of TB in South Africa. This issue is likely to confound most studies in this setting (Table 3).

\section{Incidence of active TB disease in health care workers}

Ten studies reported on the incidence of active TB disease in South African health care workers. Six of the ten studies reporting on the incidence of active TB disease in health care workers show a higher incidence of active TB disease in health care workers compared to either the general population or people in the surrounding community (Table 2) (Dwadwa et al: Health worker access to HIV/TB prevention, treatment and care services in Africa: situational analysis and mapping of routine and current best practices, unpublished) [14-18].

Both national surveys reported a higher incidence and prevalence of active TB disease in health care workers compared to the general population (Fig. 2). One national survey of 133 primary health care facilities, conducted between 2006 and 2008, reported a 2-3 times higher incidence of active TB disease in health care workers compared to the general population [15] (Table 2). The authors noted that only $40 \%$ of surveyed facilities had a TB screening program for health care workers. Many cases, therefore, are thought to go unreported [15]. The other national survey was a situational analysis conducted in 2006 that investigated health care worker access to HIV/TB prevention, treatment and care services in South Africa. This survey reported an active TB disease incidence of 1.13 to $1.47 \%$ in health care workers from various publicly funded health care facilities (Dwadwa et al: Health worker access to HIV/TB prevention, treatment and care services in Africa: situational analysis and mapping of routine and current best practices, unpublished). In contrast, in 2006 the incidence of active TB disease in the South African population was 963 per 100000 population (approximately $1 \%)[19]$.

Studies conducted in public sector hospitals in KwaZulu-Natal during the time period 1999 to 2010 found that health care workers in these facilities had significantly increased incidence of both drug sensitive and drug-resistant TB disease compared to the surrounding communities (Fig. 2) [16-18]. In contrast to this, studies conducted in the Western Cape province between 2008 and 2011, showed that health care workers from primary, secondary and tertiary care hospitals had a similar or lower incidence of active TB disease compared to the general population at the city and provincial level $[14,20]$.

Four studies reported the incidence of active TB disease for the various occupational categories [16, 18, 20, 21]. While certain categories of health care workers appeared to have higher incidence of active TB disease, only one study reported a statistically significant difference in 
Table 2 Incidence and prevalence of active TB disease and latent TB infection in health care workers in South Africa

\begin{tabular}{lll}
\hline Study ID & Study characteristics & Study outcomes \\
\hline National & & \\
Claassens et al. [15] & Study date: 2009 & Incidence of active \\
(URC report) & 133 primary health care & TB disease (smear positive) \\
& facilities in Limpopo, Eastern & 2006: $834(95 \% \mathrm{Cl} 431-1457)$ \\
& Cape, Kwazulu-Natal, & per 100,000 persons \\
& Mpumalanga and North-West & 2007: $1092(95 \% \mathrm{Cl} 647-1725)$ \\
& provinces. & per 100,000 persons \\
& No information provided & 2008: $887(95 \% \mathrm{Cl} 517-1420)$ \\
& on the health care workers & per 100,000 persons
\end{tabular}

$\begin{array}{ll}\text { Dwadwa et al: } & \text { Study date: } 2006 \\ \text { Health worker } & \text { Publicly funded health } \\ \text { access to HIV/TB } & \text { care facilities in KZN, Limpopo, } \\ \text { prevention, } & \text { North West, Northern } \\ \text { treatment and care } & \text { Cape and Western Cape } \\ \text { services in Africa: } & \text { Number of participants: 173 } \\ \text { situational analysis } & \text { health care workers from } \\ \text { and mapping of } & 10 \text { facilities } \\ \text { routine and current } & \text { Age: Not reported } \\ \text { best practices, } & \text { Sex: Not reported } \\ \text { unpublished } & \text { HIV status: Not reported } \\ \text { Situational analysis } & \text { Method of TB diagnosis: Unclear }\end{array}$

KwaZulu-Natal

Wilkinson et al. [21] Study date: not reported

Study setting: A district

hospital in rural KwaZulu-Natal

Number of participants: 725 total

number of staff at risk

22 TB cases from 1991 to 1996

Age: Mean age of staff at risk $=37$

years; Mean age of TB cases $=29.6$ years

Sex: $36 \%$ of staff at risk was female.

$64 \%$ of TB cases were female

HIV status: $59 \%$ of the staff at risk

who were tested for HIV were HIV+

$54.5 \%$ of TB cases who were tested

for HIV were HIV+

Method of diagnosing TB: Smear

microscopy, chest X-RAY

Naidoo et al. [16] Study date: 2004/2005

Study setting: Eight public sector

hospitals in Ethekwini municipality,

KwaZulu-Natal

Number of participants: 583

cases of HCWs with TB during

the study period

Age: HCWs with TB: mean $=37.9$ years

(range: 21-64)

Sex: HCWs with TB: $64 \%$ female

HIV status: Not reported

Method of diagnosing TB:

Not reported

O'Donnell

et al. [17]
A public TB referral hospital in

KwaZulu-Natal

Number of participants: 4941

total admissions of $M(X)$ DR-TB

231 confirmed HCWs (MDR-TB

$=208 ; \mathrm{XDR}-\mathrm{TB}=23$ )

Age: Median $=35$ years

Sex: $78 \%$ female
Incidence of active TB disease 2006: Between 1130 and 1470/100,000 staff had been treated for TB during 2006.

Annual incidence of active TB disease

138/100 000 (1991/1992)

Annual incidence of active

TB disease

690/100 000 (1993-1996)

Mean incidence of active

TB disease

1133/100 000 (standard

deviation: 282.8, 1999-2004)

Annual estimated incidence of MDR-TB hospital admissions among health care workers (2003-2008)

64.8/100 000

Annual estimated incidence of XDR-TB hospital admissions among health care workers (2003-2008)
General comments

To compare the TB incidence rate among healthcare workers with the general population the incidence rate was combined for all facilities. For comparison with the general population a standardised incidence ratio was calculated.

The standardised incidence ratio for smear positive TB in healthcare workers in:

2006: $2.4(95 \% \mathrm{Cl} 1.2-4.2)$

2007: $3.0(95 \% \mathrm{Cl} 1.8-4.7)$

2008: $2.3(95 \% \mathrm{Cl} 1.3-3.7)$

In 2006 the national TB case notification rates of South Africa were 719.9 per 100,000 .

1991-1996: Annual incidence of $\mathrm{TB}$ in the surrounding community was 1543/100 000 .

Mean age of affected health care workers was 29 years

No significant difference in incidence of TB disease between occupational categories

Of the $14 \mathrm{HCWs}$ who were tested for HIV, 12 were HIV-positive

Mean incidence of TB disease among general population in KZN over study period: 497/100 000

Highest incidence of TB disease in $25-29$ year olds $(2468 / 100000 ; p=0.003)$ and paramedical staff (1558/100 000; not statistically significantly different to the incidence in the other occupational categories).

Annual incidence of MDR-TB hospital admissions among the adult general population in KwaZulu-Natal: 11.9/100 000 (I.R.R. 5.56; 95 \% Cl: 4.86-6.35). Annual incidence of XDR-TB hospital admissions among adult general population in KwaZulu-Natal:

1.1/100 000 (I.R.R. 6.69; 95

$\% \mathrm{Cl}: 4.38-10.2$ 
Table 2 Incidence and prevalence of active TB disease and latent TB infection in health care workers in South Africa (Continued)

\begin{tabular}{|c|c|c|c|}
\hline & $\begin{array}{l}\text { HIV status: } 55 \% \text { of HCW with } \\
\text { M(X) DR-TB were HIV+ } \\
\text { Method of diagnosing TB: } \\
\text { Culture confirmed TB with } \\
\text { MTB drug susceptibility testing }\end{array}$ & $7.2 / 100000$ & \\
\hline $\begin{array}{l}\text { Tudor } \\
\text { et al. [18] }\end{array}$ & $\begin{array}{l}\text { Study date: } 2011 \\
\text { Three district hospitals in } \\
\text { KwaZulu-Natal, South Africa, } \\
\text { with specialized drug-resistant } \\
\text { tuberculosis (TB) wards } \\
\text { Number of participants: } 1427 \\
\text { HCW occupational health records } \\
\text { Age: Median = } 39 \text { years } \\
\text { Sex: } 78.05 \% \text { female } \\
\text { HIV status: } 24 \% \text { of HCWs } \\
\text { with TB HIV+ } \\
\text { Method of diagnosing } \\
\text { TB: Not reported }\end{array}$ & $\begin{array}{l}\text { Incidence of active TB disease } \\
\text { 1958/100 } 000 \text { (2010) } \\
\text { 2006-2010: } 112(8.53 \%) \\
\text { cases of TB, of which } 14 \\
\text { (12.5\%) cases were } \\
\text { drug-resistant TB. }\end{array}$ & $\begin{array}{l}\text { Incidence of TB disease among } \\
\text { the general population of KwaZulu-Natal } \\
\text { was } 1142 / 100000 \text { (2011). Throughout } \\
\text { the study period health care workers } \\
\text { had significantly higher annual TB } \\
\text { incidence rate ratios (IRR) for each } \\
\text { year of the study compared to that } \\
\text { of the general population in KwaZulu-Natal. } \\
\text { Incidence of active TB in South Africa: } \\
981 / 100000 \text { (2010) }\end{array}$ \\
\hline \multicolumn{4}{|l|}{ Western Cape } \\
\hline $\begin{array}{l}\text { Adams: Prevalence } \\
\text { and determinants } \\
\text { of TB infection in } \\
\text { health care } \\
\text { workers, } \\
\text { unpublished }\end{array}$ & $\begin{array}{l}\text { Study date: } 2009-2011 \\
7 \text { primary and secondary level } \\
\text { health care facilities in the } \\
\text { Western Cape province } \\
\text { Number of participants: } 505 \\
\text { Age: }<30 \text { years ( } 25 \%) ; 31-40 \text { years } \\
\text { (27\%); } 41-50 \text { years ( } 27 \%) ; \\
>50 \text { years ( } 22 \%) \\
\text { Sex: } 74 \% \text { female } \\
\text { HIV status: Primary level } \\
\text { staff } 19 \% \text { HIV+; Secondary } \\
\text { level staff } 2 \% \text { HIV+ } \\
\text { Method of diagnosing TB: } \\
\text { TB infection: TST, QFT-GIT, } \\
\text { TSPOT.TB. TB disease: TB } \\
\text { symptom screen, Chest X-Ray } \\
\text { and } 2 \times \text { sputum culture. }\end{array}$ & $\begin{array}{l}\text { Annual incidence of active } \\
\text { TB disease } \\
\text { 900/100 000; } 95 \% \text { Cl: 0.2-2.6 } \\
\text { (2009-2011) } \\
\text { Prevalence of active } \\
\text { TB disease } \\
\text { 1400/100 } 000 \text { (2009-2011) } \\
\text { Prevalence of latent TB infection } \\
84 \% \text { (TST; } 2009-2011 \text { ) } \\
\text { Annual incidence of latent } \\
\text { TB infection } \\
38 \% \text { of HCWs converted } \\
\text { from TST negative to positive } \\
\text { (2009-20110) }\end{array}$ & $\begin{array}{l}\text { Annual incidence rate in Cape } \\
\text { Town 799/100 } 000 \text { population } \\
\text { and Western Cape 935/100 } 000 \\
\text { population (2008-2011) } \\
3 / 5 \text { HCWs with active TB were HIV+ } \\
9 \% \text { of HCWs reported being } \\
\text { diagnosed with or on treatment } \\
\text { for diabetes } \\
\text { Annual incidence of latent } \\
\text { TB infection } \\
\text { QFT-GIT } \\
\text { conversion rate } 22 \% \\
\text { reversion rate } 7 \% \\
\text { T-SPOT.TB } \\
\text { conversion rate } 22 \% \\
\text { reversion rate } 16 \%\end{array}$ \\
\hline Ayuk et al. [20] & $\begin{array}{l}\text { Study date: } 2008-2011 \\
\text { Tygerberg Academic Hospital, } \\
\text { Western Cape province } \\
\text { Number of participants: } 249 \\
\text { Age: Mean = } 43.8 \text { (range: } 23-60 \text { ) years } \\
\text { Sex: } 71.4 \% \text { female } \\
\text { HIV status: } 30 \% \text { HIV+; } 63 \% \text { HIV-; } \\
6 \% \text { unknown } \\
\text { Method of diagnosing TB: smear+; } \\
\text { culture+, histology and symptoms }\end{array}$ & $\begin{array}{l}\text { Mean annual incidence } \\
\text { rate of active TB disease } \\
\text { 2008-2011: } 397 / 100000 \\
\text { population ( } 95 \% \mathrm{Cl}: 307-505 \\
\text { per } 100 \text { 000; all health care workers) } \\
\text { Incidence rate of active TB disease } \\
\text { Housekeeping staff: } 1181 / 100000 \\
\text { Nurses: } 324 / 100000 \\
\text { Doctors: } 194 / 100000\end{array}$ & $\begin{array}{l}\text { Annual incidence rate in Cape } \\
\text { Town } 799 / 100000 \text { population } \\
\text { and Western Cape } 935 / 100000 \\
\text { population } \\
\text { Housekeeping staff incidence } \\
\text { rate of active TB disease approximately } \\
3 \text { times ( } 95 \% \mathrm{Cl} \text { : } 2.7-3.3 \text { ) that of the } \\
\text { entire workforce, } 3.6 \text { times ( } 95 \% \mathrm{Cl}: 3.2-4.1 \text { ) } \\
\text { that of nurses and } 6.1 \text { times ( } 95 \% \mathrm{Cl}: 5.2-7.1 \text { ) } \\
\text { that of doctors. }\end{array}$ \\
\hline $\begin{array}{l}\text { Kranzer } \\
\text { et al. [6] }\end{array}$ & $\begin{array}{l}\text { Study date: } 2008 / 2009 \\
\text { Mobile HIV testing unit } \\
\text { (the TUTU tester) provided } \\
\text { HIV testing, CD4 counts and } \\
\text { TB screening to TB and } \\
\text { antiretroviral adherence } \\
\text { supporters employed by } \\
\text { the TB/HIV Care Association } \\
\text { in Cape Town on } 8 \text { days in } \\
8 \text { venues in the Western } \\
\text { Cape province } \\
\text { Number of participants: } \\
215 \text { community health } \\
\text { workers (CHW) were offered } \\
\text { HIV and TB testing } \\
\text { Age: Most common age } \\
\text { group was } 40-49 \text { years old }(N=72,33 \%) \\
\text { Sex: All female } \\
\text { HIV status: } 42 \text { CHW HIV+ }(20 \%) \\
\text { Method of diagnosing TB: } \\
\text { Smear and culture testing }\end{array}$ & $\begin{array}{l}\text { Prevalence of active TB disease } \\
5 \%(10 / 215 ; 2008-2009)\end{array}$ & \\
\hline
\end{tabular}


Table 2 Incidence and prevalence of active TB disease and latent TB infection in health care workers in South Africa (Continued)

\begin{tabular}{|c|c|c|c|}
\hline Naidoo et al. [24] & $\begin{array}{l}\text { Date of study not reported } \\
\text { Western Cape } \\
\text { Number of participants: } 100 \\
\text { randomly selected practicing } \\
\text { dentists; } 78 \% \text { response rate. } \\
\text { Age: Mean = } 40 \text { years } \\
\text { Sex: } 80 \% \text { male } \\
\text { HIV status: Not reported } \\
\text { Method of diagnosing TB: } \\
\text { Mantoux and multipuncture tests }\end{array}$ & $\begin{array}{l}\text { Prevalence of latent TB infection } \\
33 \% \text { (No dates provided) }\end{array}$ & \\
\hline Mehtar et al. [29] & $\begin{array}{l}\text { Study date: } 2010 \\
\text { Retrospective review of } \\
\text { OATB case reports at Tygerberg } \\
\text { Academic Hospital in the Western Cape } \\
\text { Number of participants: } 67 \\
\text { cases of OATB reported } \\
\text { during study period 2008-2010 } \\
\text { Age: Not reported } \\
\text { Sex: Not reported } \\
\text { HIV status: Not reported } \\
\text { Method of TB diagnosis: } \\
\text { Smear microscopy }\end{array}$ & $\begin{array}{l}\text { Number of occupationally acquired } \\
\text { TB cases } \\
\text { 2008: } 27 \text { TB cases ( } 17 \text { ancilliary staff) } \\
\text { 2009: } 21 \text { TB cases ( } 7 \text { ancilliary staff) } \\
\text { 2010: } 19 \text { TB cases ( } 13 \text { ancilliary staff) } \\
\text { Pulmonary TB among health care } \\
\text { workers } \\
38.5 \% \text { (2008) } \\
27.8 \%(2010)\end{array}$ & \\
\hline $\begin{array}{l}\text { Jarand } \\
\text { et al. [25] }\end{array}$ & $\begin{array}{l}\text { Study date: } 1996-2008 \\
\text { Retrospective case record } \\
\text { review of patients with XDR-TB } \\
\text { from Eastern and Western } \\
\text { Cape provinces } \\
\text { Number of participants: } \\
334 \text { XDR-TB patients (10 HCWs with XDR-TB) } \\
\text { Median age: } 41 \text { (26-50) } \\
\text { Sex: } 90 \% \text { female } \\
\text { HIV status: } 2 / 10 \text { HIV+ } \\
\text { Method of TB diagnosis: } \\
\text { sputum culture }\end{array}$ & $\begin{array}{l}10 \text { of the } 334 \text { patients with } \\
\text { diagnosed with XDR-TB between } \\
1996 \text { and } 2008 \text { were health } \\
\text { care workers }\end{array}$ & $\begin{array}{l}\text { 5/10 were nurses } \\
4 / 10 \text { HCWs died } \\
\text { HCW with XDR TB: } 26-50 \\
\text { years old; } 60 \% \text { nursing staff; } \\
80 \% \text { HIV-negative }\end{array}$ \\
\hline \multicolumn{4}{|l|}{ Gauteng } \\
\hline $\begin{array}{l}\text { McCarthy } \\
\text { et al. [22] } \\
\text { Van Rie } \\
\text { et al. [23] }\end{array}$ & $\begin{array}{l}\text { Study date: 2008-2009 } \\
\text { Gauteng } \\
\text { Number of participants: } \\
79 \text { medical students and } \\
120 \text { healthcare workers } \\
\text { Age: Medical students median } \\
\text { age } 22 \text { (22-24) } \\
\text { HCW median age } 36 \text { (28-46) } \\
\text { Sex: Medical students = 44 \% males } \\
\text { HCW = } 10 \% \text { males } \\
\text { HIV status: Medical students = } 0 \% \\
\text { HIV+; HCW = } 18.3 \% \text { HIV+ } \\
\text { Method of diagnosing latent TB: } \\
\text { TST and IGRA assay } \\
\text { (Quantiferon-TB Gold In-tube) }\end{array}$ & $\begin{array}{l}\text { Incidence of latent TB } \\
\text { infection (2008-2009) } \\
26 \% \text { (29 per } 100 \text { person } \\
\text { years, } 95 \% \text { Cl: } 20-44 \text {, IGRA) } \\
27 \% \text { ( } 29 \text { per } 100 \text { person } \\
\text { years, 95\%Cl: } 19-42, \text { TST) } \\
\text { Prevalence of latent TB } \\
\text { infection (2008) } \\
45 \% \text { (95\%Cl: 38-53; IGRA+) } \\
48 \% \text { (95\%Cl: 42-57; TST+) } \\
\text { Incidence of active } \\
\text { TB disease (2008-2009) } \\
1.8 / 100 \text { person years } \\
\text { (95\%Cl: } 0.45-7.2) \text { among HCWs }\end{array}$ & $\begin{array}{l}\text { HCWs LTBI prevalence was } \\
\text { two-to four-fold higher than } \\
\text { medical students } \\
\text { TST: } 56.7 \% \text { vs. } 26.6 \% \\
\text { IGRA: } 69.2 \% \text { vs. } 15.2 \%\end{array}$ \\
\hline \multicolumn{4}{|l|}{ Limpopo } \\
\hline Malangu et al. [5] & $\begin{array}{l}\text { Study date: not reported } \\
\text { Data on health care acquired } \\
\text { infection submitted to the } \\
\text { Compensation Commissioner } \\
\text { of the Limpopo province by } \\
\text { a health care worker } \\
\text { Number of participants: } \\
56 \text { cases of infectious diseases } \\
\text { reported over } 2 \text { years. } \\
\text { Age: } 42.7 \text { years (mean) }\end{array}$ & $\begin{array}{l}\text { 2007-2009: Of the } 56 \text { reported } \\
\text { cases of infectious diseases } 47 \\
\text { (83.9\%) were TB cases. } \\
\text { 30/47 TB cases were nurses } \\
\text { 8/47 TB cases were cleaning staff }\end{array}$ & $\begin{array}{l}\text { Among health professionals, } \\
\text { nurses most likely to acquire } \\
\text { TB disease; Among non-health } \\
\text { professionals cleaning staff most } \\
\text { likely to acquired TB disease } \\
\text { Cases were defined as reports } \\
\text { about any healthcare acquired } \\
\text { infection as submitted for } \\
\text { compensation by healthcare } \\
\text { workers of Limpopo province. }\end{array}$ \\
\hline
\end{tabular}

HIV status: Not reported

Method of TB diagnosis: Unclear
Prevalence of latent TB infection

Number of occupationally acquired

2009: 21

2010: 19 TB cases (13 ancilliary staff)

$\mathrm{B}$ among health care

$38.5 \%(2008)$

$5 / 10$ were nurse

years old; $60 \%$ nursing staff; $80 \%$ HIV-negative idence of latent $T B$

$45 \%$ (95\%Cl: 38-53; IGRA+)

$48 \%$ (95\%Cl: 42-57; TST+)

idence of active

$8 / 100$ person years

(95\%Cl: 0.45-7.2) among HCWs

2007-2009: Of the 56 reported diseases 47

30/47 TB cases were nurses

8/47 TB cases were cleaning staff two-to four-fold higher than medical students

TST: $56.7 \%$ vs. $26.6 \%$

IGRA: $69.2 \%$ vs. $15.2 \%$ 
Table 2 Incidence and prevalence of active TB disease and latent TB infection in health care workers in South Africa (Continued)

\begin{tabular}{|c|c|c|c|}
\hline \multicolumn{4}{|l|}{ Mpumalanga } \\
\hline Balt et al. [26] & $\begin{array}{l}\text { Study date: Not reported } \\
\text { Study setting: } 4 \text { dedicated TB } \\
\text { centres (SANTA centres) in } \\
\text { Mpumalanga } \\
\text { Details of study participants and } \\
\text { method of TB diagnosis not reported }\end{array}$ & $\begin{array}{l}\text { Annual incidence of TB } \\
\text { disease (1986-1997) } \\
\text { 275/100 } 000 \text { (95\% } \\
\text { confidence interval: 33-991) } \\
\text { Between } 1986 \text { and 1997: } 2 \\
\text { nurses with active TB }\end{array}$ & $\begin{array}{l}\text { The incidence of TB in the general } \\
\text { population of Mpumalanga at the } \\
\text { time estimated to be } 286 / 100000 \\
\text { Affected nurses were } 36 \text { and } 56 \\
\text { years old; both nurses had non-insulin } \\
\text { dependant diabetes }\end{array}$ \\
\hline
\end{tabular}

incidence of active TB disease between the various occupational categories [20]. In this study, conducted in a tertiary hospital in the Western Cape, the incidence of active TB disease in the housekeeping staff was three times that of the entire health care workforce (risk ratio: 3, 95\%CI: 2.7-3.3) and nurses (risk ratio: 3.7, 95\%CI: 3.2-4.1) and six times that of doctors (risk ratio: 6.1, 95\%CI: 5.2-7.1) [20]. Furthermore, the incidence of active TB disease was statistically significantly greater in nurses compared to doctors (324/100 000 population vs. 194/100 000 population, risk ratio: $1.7,95 \% \mathrm{CI}: 1.4-2)$ [20] (Table 2).

\section{Prevalence of active TB disease in health care workers}

Two studies provide data on the prevalence of active TB disease in South African health care workers. Active TB disease was less prevalent in health care workers working in health care facilities (1.4\%) [14] compared to those working in the community (5\%) [6]. Both of the studies report a higher prevalence of TB disease in health care workers compared to the prevalence in the surrounding community (population-based prevalence survey reported a TB disease prevalence of $3 \%[6]$ ) or general population (national prevalence of active TB disease for 2010 was estimated to be $0.8 \%[19])[6,14]$.

\section{Incidence of latent TB infection in health care workers}

Two studies provided information on the incidence of latent $\mathrm{TB}$ infection in health care workers in South Africa. Health care workers from primary and secondary level health care facilities in the Western Cape province had an annual rate of latent TB infection of $38 \%$ (95\%CI: $22-56 \%$, converted from negative to positive TST during 2009-2011) [14]. In Gauteng province, a cohort of health care workers and medical students working in three public sector health care facilities had an annual incidence of latent TB infection of $27 \%$ (25/93 converted from negative to positive TST during 20082009) [22].

\section{Prevalence of latent TB infection in health care workers}

Three studies reported on prevalence of latent TB infection in health care workers in South Africa. The prevalence of latent $\mathrm{TB}$ infection in health care workers ranged from $84 \%$ (TST-positive, health care workers from primary and secondary health care facilities in the Western Cape; 2009) [14] to 48 \% (TST-positive, medical students and health care workers from public sector health care facilities in Gauteng; 2008) [23]. Two of the three studies reporting on prevalence of latent TB infection were conducted in the Western Cape [14, 24]. In Gauteng, the prevalence of latent $\mathrm{TB}$ infection was higher among HCWs than medical students (56.7 \% vs. $26.6 \%$, respectively; $p<0.0001$ ) [23].

\section{Drug-resistant TB in health care workers}

Two studies specifically report on drug-resistant TB in health care workers in South Africa. One study reported specifically on the incidence of hospital admissions, to a public referral hospital in KwaZulu-Natal, for multidrugresistant or extensively drug resistant TB disease among health care workers [17]. In this study the annual estimated incidence of hospital admission for multidrug resistant (MDR)-TB among health care workers was more than 5 times that of the adult general population and more than 6 times of that of general population for extensively drug resistant (XDR)-TB (Table 2). A further retrospective case record review reported that ten of the 334 patients diagnosed with (XDR)-TB between 1996 and 2008 in the Eastern and Western Cape were health care workers [25].

\section{Risk factors for occupational TB in health care workers}

The findings of the five studies investigating the risk factors associated with active TB disease or latent $\mathrm{TB}$ infection (LTBI) in health care workers are presented in Table 4.

\section{Age of health care worker}

There wasn't a consistent association across the studies with regards to health care worker age and risk of active TB disease or latent TB infection. Furthermore, the particular age category of health care worker most affected by active TB disease or latent TB infection also differed between studies (Table 4) and only two studies reported a significant difference in the incidence of active TB disease between the various age categories. Ayuk et al. [20] reported that health care workers 40 years or older had a significantly higher incidence of active TB disease 
Table 3 Risk of bias assessment for studies reporting on incidence and prevalence of active TB disease and latent TB infection in health care workers

\begin{tabular}{|c|c|c|c|}
\hline Study ID & Risk of selection bias ${ }^{a}$ & $\begin{array}{l}\text { Risk of detection/information bias } \\
\text { for each outcome }\end{array}$ & Risk of confounding ${ }^{c}$ \\
\hline
\end{tabular}

Prospective cohort study

Adams: Prevalence and determinants of TB infection in health care workers, unpublished

UNCLEAR: Participation in the study was voluntary. 505/764 HCWs participated in the study.
McCarthy et al. [22] (linked to Van Rie et al. [23])

Claassens et al. [15]

Dwadwa et al: Health worker access to HIV/TB prevention, treatment and care services in Africa: situational analysis and mapping of routine and current best practices, unpublished

Kranzer et al. [6]

Naidoo et al. [24]

Retrospective cohort study

Balt

et al. [26]

Malangu et al. [5]
UNCLEAR: Participation in the study was voluntary. 120/450 eligible HCWs and 79/296 eligible medical students participated in the study. Risk factors for TB: HIGH (HCWs
completed questionnaires which are
prone to information bias)

UNCLEAR: Not all HCWs completed questionnaire

Incidence and prevalence of TB disease: LOW

Risk factors for TB: HIGH (HCWs completed questionnaires which are

LOW: Although authors report that health care facilities were randomly selected there is no explanation of how the randomisation process was conducted.

UNCLEAR: Six of the facilities were randomly selected although there is no explanation of how this was conducted. Four of the facilities were specifically selected based on current best practice as recommended by the Department of Health and AIDS and TB Directorates.

UNCLEAR: It is not clear how the community health workers (CHWs) were selected, if all of the CHW were selected to participate or if participation was voluntary

UNCLEAR: Although authors state Prevalence of LTBI: LOW (LTBI that a randomly selected sample of diagnosed with Mantoux tests) dentists was approached to participate in the study, it is not clear how this randomisation process was conducted. Only 78 of the 100 dentists participated

Prevalence of TB disease: LOW (standard TB diagnostic techniques used)

each health care facility a questionnaire was completed by the facility manager to indicate the number of HCWs who were registered in that facility and who had been on TB treatment from January 2006 to December 2008.

Number of TB cases: HIGH (Data obtained from questionnaires and interviews

LOW: Detailed review of health staff Incidence of TB disease: LOW records at the four dedicated TB centres

LOW: A pre-designed data collection form was used to extract data from claims

submitted to the Compensation

Commissioner from January 2007

to December 2009

Cases of TB disease: LOW (Data based on reported cases of TB. However, it is well known that there is underreporting of TB among HCWs with regards to occupational diseases. This may introduce

UNCLEAR: Community vs.

occupational exposure to TB; HIV status of all of the HCWs not known prone to information bias) (n) UNCLEAR: Community vs.
occupational exposure to TB. However, HIV status of all participants was assessed.

UNCLEAR: Community vs. occupational exposure to TB; HIV status of all of the HCWs not known

UNCLEAR: Community vs. occupational exposure to TB; HIV status of all of the HCWs not known

UNCLEAR: Community vs. occupational exposure to TB

UNCLEAR: HIV status of all of the HCWs not known

UNCLEAR: It is not clear where the dentists practiced or the demographics of their patients; Community vs occupational exposure to TB; HIV status of all of the HCWs not known

UNCLEAR: Community vs. occupational exposure to TB detection bias and affect the external validity of the study)
UNCLEAR: possible underreporting of TB cases; Community vs occupational exposure to TB; HIV status of all of the HCWs not known 
Table 3 Risk of bias assessment for studies reporting on incidence and prevalence of active TB disease and latent TB infection in health care workers (Continued)

\begin{tabular}{ll}
\hline Jarand & LOW: Retrospective case record \\
et al. [25] & review of all patients with XDR-TB \\
& in Eastern and Western Cape prov- \\
& ince from 1996 to 2008 \\
Mehtar et al. [29] & LOW: Retrospective review of \\
& occupationally acquired TB case \\
& reports
\end{tabular}

Naidoo et al. [16]

O’Donnell et al. [17]

Tudor et al. [18]

Van Rie et al. [23]

Wilkinson et al. [21]
LOW: Retrospective record review. All HCW with TB treated at 8 specified public sector hospitals were included if records confirmed HCW status

UNCLEAR: Although hospital database was used to identify MDR-TB and XDR-TB admissions the study relied on $\mathrm{HCW}$ self-reporting their occupation.

LOW: Data abstracted from medical charts using a standardized chart audit form

UNCLEAR: Participation in the study was voluntary. 120/450 eligible HCWs and 79/296 eligible medical students participated in the study.

LOW: Staff TB data was extracted confidentially from the anonymized tuberculosis control programme register. occupational health employee
UNCLEAR: it is not known how study authors determined whether patients were health care workers

Cases of TB disease: LOW (Data based on reported cases of OATB. However, it is well known that there is underreporting of TB among HCWs with regards to occupational diseases. This may introduce detection bias and affect the external validity of the study)

Incidence of TB disease: LOW (However, it is possible that HCWs seeking TB treatment may not have stated their occupation, resulting in underreporting of TB cases and information bias)

Incidence of TB disease: LOW (However, it is possible that HCWs seeking TB treatment may not have stated their occupation, resulting in underreporting of TB cases and information bias)

Incidence of TB disease: LOW

\section{Prevalence of LTBI: LOW}

LTBI was diagnosed using TST and IGRAs

Incidence of TB disease: LOW (Case ascertainment is known to be complete because tuberculosis treatment cannot be obtained anywhere else in the district and all staff illness episodes are recorded in personnel files)

\section{UNCLEAR: Community vs. occupational exposure to TB}

UNCLEAR: Underreporting of TB cases; Community vs occupational exposure to TB; HIV status of all of the HCWs not known

UNCLEAR: Underreporting of TB cases; Community vs occupational exposure to TB; HIV status of all of the HCWs not known

UNCLEAR: Underreporting of TB cases; Community vs occupational exposure to TB; HIV status of all of the HCWs not known

UNCLEAR: Underreporting of TB cases; Community vs occupational exposure to TB; HIV status of all of the HCWs not known

UNCLEAR: Community vs occupational exposure to TB. HIV status of all participants was assessed.

UNCLEAR: Community vs occupational exposure to TB; HIV status of all of the HCWs not known

LOW low risk of bias, HIGH high risk of bias UNCLEAR unclear risk of bias

${ }^{a}$ Selection bias refers to systematic differences between baseline characteristics of the groups that are compared or characteristics of those who participate in the study and those who don't. It is important that the group described is representative of the population of interest

${ }^{b}$ Detection bias/information bias refers to systematic differences between groups in how outcomes are determined. Participant's self-reported outcomes are usually associated with a high risk of detection or information bias

${ }^{c}$ Confounding factors can cause or prevent the outcome of interest, are not intermediate variables, and are not associated with the factor(s) under investigation. Confounding factors result in situations in which the effects of two processes are not separated, or the contribution of causal factors cannot be separated, or the measure of the effect of exposure or risk is distorted because of its association with other factors influencing the outcome of the study

compared to health care workers younger than 40 years (incidence rate difference: 206/100 000, $p=0.038$ ). In Naidoo et al. [16], health care workers aged $25-29$ years had a significantly higher incidence of active TB disease compared to all other age groups (mean incidence: $2467 / 100000, \mathrm{SD} 1184, p=0.01$ ). Of the five studies reporting on this, two studies found a significant association between age and risk for latent TB infection. In Adams et al. [14] health care workers in a particular age group (31-40 years) had a significantly increased odds of acquiring latent TB infection (odds ratio (OR): 2.08 95\%CI: 1.04, 4.17). McCarthy et al. [22] found that health care workers 31 years and older had a significantly higher risk of acquiring latent TB infection (measured by IGRA; crude IRR: 2.3 95\%CI: 0.9, 5.8).

\section{Duration of employment}

Both of the studies that assessed the relationship between duration of employment and incidence of active TB disease found no significant association $[18,20]$. In the one study that assessed the relationship between duration of employment and incidence of latent TB infection, duration of employment of greater than 20 years in a primary level care facilities was statistically significantly associated with an increased risk of latent TB infection (TST positivity; OR: 3.47; 95 \% CI: 1.01-11.97) [14]. 


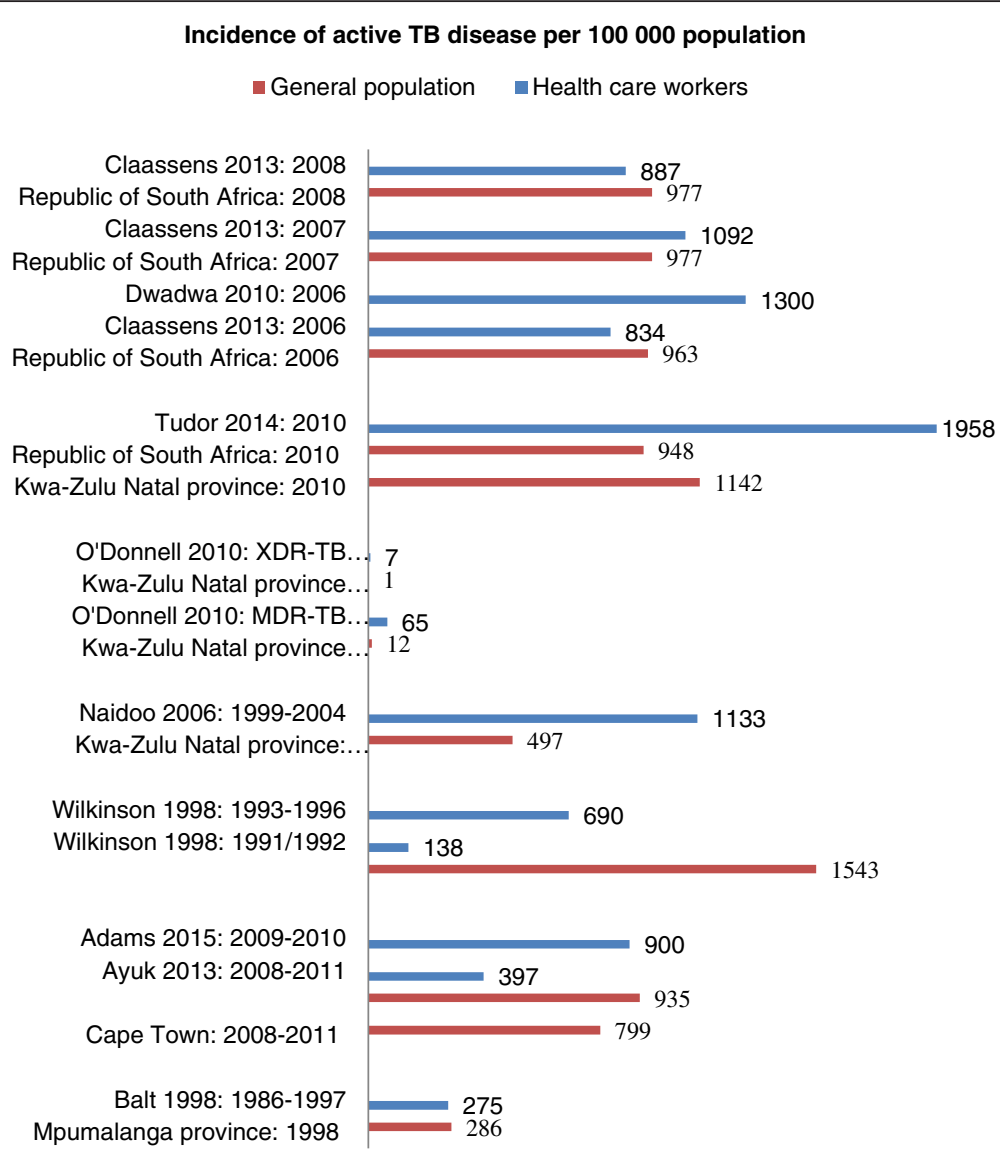

Fig. 2 Bar graph comparing incidence of active TB disease in health care workers and general population. Dwadwa et al: Health worker access to HIV/TB prevention, treatment and care services in Africa: situational analysis and mapping of routine and current best practices, unpublished: Data presented is an average of the combined incidence of active TB disease in health care workers from best practice and randomly selected health care facilities; all incidence data for general population in the Republic of South Africa was obtained from the World Health Organisation Global TB database [19]; data on the incidence of active TB disease in the surrounding community was obtained from the individual studies; MDR-TB: multi-drug resistant tuberculosis; XDR-TB: extensively-drug resistant tuberculosis

\section{Health care worker occupation and work location}

One study assessed the relationship between health care worker occupation and incidence of active TB disease and found no significant association for the various occupation categories [18]. No significant association was found between health care worker job category and risk of latent TB infection in the one study that reported on this relationship [23].

Tudor et al. [18] reported that compared to health care workers with no history of working in these areas, health care workers with a history of working in the TB ward (IRR 2.03, $95 \%$ CI 1.11-3.71), paediatric ward (IRR 1.82, $95 \%$ CI 1.07-3.10), the outpatient department (IRR 2.08, $95 \%$ CI 1.23-3.52) and the stores department (IRR 2.38, $95 \%$ CI 1.06-5.34) had a significantly increased incidence of active TB disease.

\section{HIV status}

Two studies reported on the relationship between HIV status and the incidence of active TB disease $[18,20]$.
Health care workers living with HIV had significantly greater odds of developing TB (Tudor et al. [18]: adjusted OR 4.11; 95 \% CI: 1.95-8.67; Ayuk et al.: adjusted OR= 50.94; adjusted $95 \%$ CI: 5.26-493.73, $p=0.003)[18,20]$.

Two studies assessed the relationship between HIV status and incidence of latent TB infection [14, 22]. Adams et al. [14] showed that HIV-positive health care workers were less likely to have a positive TST (OR: 0.41, 95 \%CI: 0.18-0.92). In contrast, McCarthy et al. [22] did not find a significant association between HIV status and incidence of latent TB infection as measured by either IGRA assay or TST.

Only one study reported on the association between HIV status and the prevalence of latent TB infection [23]. Although HIV-negative health care workers were less likely to have a positive TST (OR 0.28; $95 \%$ CI $0.10-0.74)$, this association was not significant after adjustment for age, job category and TB knowledge score [23]. 
Table 4 Risk factors associated with active TB disease or latent TB infection (LTBI) in health care workers

\begin{tabular}{|c|c|c|c|c|c|c|}
\hline Study ID & Age & Employment duration & Occupation & HIV status & Diabetes & TB IPC training \\
\hline \multicolumn{7}{|c|}{ Incidence of active TB disease } \\
\hline $\begin{array}{l}\text { Ayuk } \\
\text { et al. [20] }\end{array}$ & $\begin{array}{l}\text { Not significantly } \\
\text { associated with } \\
\text { odds of acquiring } \\
\text { TB disease; age } \\
\text { 40-49 years most } \\
\text { affected by TB } \\
\text { disease }\end{array}$ & $\begin{array}{l}\text { Not significantly } \\
\text { associated with odds } \\
\text { of acquiring TB disease }\end{array}$ & Not assessed & $\begin{array}{l}\text { HIV+ HCWs have } \\
\text { significantly } \\
\text { increased odds of } \\
\text { acquiring TB disease } \\
\text { (OR: } 67.08 \text { 95\%Cl: } \\
7.5-596.6 \text { ) }\end{array}$ & $\begin{array}{l}\text { Not } \\
\text { significantly } \\
\text { associated } \\
\text { with odds of } \\
\text { acquiring TB } \\
\text { disease (OR: } \\
\text { 1.7 95\%Cl: } \\
0.8-3.8 \text { ) }\end{array}$ & $\begin{array}{l}\text { No previous training in } \\
\text { TB prevention (OR: } 2.97 \\
95 \% \text { Cl: } 1.2-7.7) \text {; no } \\
\text { knowledge of TB risk } \\
\text { profile of work place (OR: } \\
8.795 \% \mathrm{Cl}: 1.1-67.96) \\
\text { significantly associated } \\
\text { with increased odds of } \\
\text { acquiring TB disease }\end{array}$ \\
\hline $\begin{array}{l}\text { Tudor } \\
\text { et al. [18] }\end{array}$ & $\begin{array}{l}\text { Not significantly } \\
\text { associated with } \\
\text { incidence of TB } \\
\text { disease }\end{array}$ & $\begin{array}{l}\text { Years worked in } \\
\text { hospital not } \\
\text { significantly associated } \\
\text { with incidence of TB } \\
\text { disease }\end{array}$ & $\begin{array}{l}\text { No significant } \\
\text { association between } \\
\text { occupational category } \\
\text { and incidence of TB } \\
\text { disease; history of } \\
\text { working in TB ward } \\
\text { significantly associated } \\
\text { with increased } \\
\text { incidence of TB disease } \\
\text { (IRR: } 2.8795 \% \text { Cl: } 1.67- \\
\text { 4.93) }\end{array}$ & $\begin{array}{l}\text { HIV-positivity } \\
\text { significantly } \\
\text { associated with } \\
\text { increase incidence of } \\
\text { TB disease (adjIRR: } \\
3.2 \text { 95\%Cl: } 1.54-6.66 \text { ) }\end{array}$ & $\begin{array}{l}\text { Not reported } \\
\text { on }\end{array}$ & Not reported on \\
\hline \multicolumn{7}{|c|}{ Incidence of latent TB infection } \\
\hline $\begin{array}{l}\text { Adams } \\
\text { et al. [14] }\end{array}$ & $\begin{array}{l}\text { Age } 31-40 \text { years } \\
\text { significantly } \\
\text { associated with } \\
\text { increased odds of } \\
\text { LTBI (OR: } 2.08 \\
\text { 95\%Cl: } 1.04,4.17)\end{array}$ & $\begin{array}{l}\text { Employment in primary } \\
\text { level health care } \\
\text { facility }>20 \text { years } \\
\text { significantly associated } \\
\text { with increased odds of } \\
\text { LTBI (OR: } 3.47,95 \% \text { Cl } \\
1.01-11.97 \text { ) }\end{array}$ & Not assessed & $\begin{array}{l}3 / 5 \text { HCWs with TB } \\
\text { disease were HIV+ } \\
\text { HIV+ significantly } \\
\text { associated with } \\
\text { decreased odds of } \\
\text { TSTpos (OR: } 0.41 \\
\text { 95\%Cl: } 0.17-0.95 \text { ) }\end{array}$ & $\begin{array}{l}\text { Not } \\
\text { significantly } \\
\text { associated } \\
\text { with odds of } \\
\text { LTBI }\end{array}$ & $\begin{array}{l}\text { In secondary level staff } \\
\text { "some training on self- } \\
\text { protection from TB infec- } \\
\text { tion" significantly associ- } \\
\text { ated with decreased } \\
\text { odds of LTBI (OR: } 0.38 \\
95 \% C l \text { : } 0.16-0.91 \text { ) }\end{array}$ \\
\hline $\begin{array}{l}\text { McCarthy } \\
\text { et al. [22] }\end{array}$ & $\begin{array}{l}\text { IGRA: } \geq 31 \text { years } \\
\text { significantly } \\
\text { associated with } \\
\text { increased risk of } \\
\text { latent TB infection } \\
\text { (crude IRR: } 2.3 \\
\text { 95\%Cl: } 0.9,5.8 \text { ) } \\
\text { TST: No significant } \\
\text { association }\end{array}$ & Not reported on & $\begin{array}{l}\text { IGRA: HCWs had a } \\
\text { significantly greater risk } \\
\text { of acquiring latent TB } \\
\text { infection (crude IRR: } \\
4.32,95 \% \text { Cl: } 1.7-12.2 \text { ) } \\
\text { TST: No significant } \\
\text { association }\end{array}$ & $\begin{array}{l}\text { No significant } \\
\text { association between } \\
\text { HIV status and risk of } \\
\text { latent TB infection } \\
\text { with both IGRA and } \\
\text { TST }\end{array}$ & $\begin{array}{l}\text { Not reported } \\
\text { on }\end{array}$ & $\begin{array}{l}\text { IGRA: Higher TB } \\
\text { knowledge score (crude } \\
\text { IRR: 0.4, 95\%Cl: 0.1, 1.3) } \\
\text { and TB infection control } \\
\text { training (crude IRR: } 0.4 \text {, } \\
95 \% C l \text { : 0.1, 1.2) } \\
\text { significantly reduced risk } \\
\text { of latent TB infection } \\
\text { TST; TB infection control } \\
\text { practiced by participants } \\
\text { significantly reduced risk } \\
\text { of latent TB infection } \\
\text { (crude IRR: } 0.4,95 \% C l \text { : } \\
0.1,1.3 \text { ) }\end{array}$ \\
\hline \multicolumn{7}{|c|}{ Prevalence of latent TB infection } \\
\hline $\begin{array}{l}\text { Van Rie } \\
\text { [23] }\end{array}$ & $\begin{array}{l}\text { Prevalence of LTBI } \\
\text { No significant } \\
\text { association with } \\
\text { LTBI in medical } \\
\text { students or health } \\
\text { care workers }\end{array}$ & Not reported on & $\begin{array}{l}\text { Not assessed in medical } \\
\text { students } \\
\text { No significant } \\
\text { association with LTBI in } \\
\text { health care workers }\end{array}$ & $\begin{array}{l}\text { Medical students all } \\
\text { HIV-negative } \\
\text { HIV-negative health } \\
\text { care workers } \\
\text { significantly reduced } \\
\text { odds of TST positive } \\
\text { (OR: } 0.28 \text { 95\%Cl: } 0.1 \text { - } \\
0.74 \text { ) }\end{array}$ & $\begin{array}{l}\text { Not reported } \\
\text { on }\end{array}$ & $\begin{array}{l}\text { Medical students: TB } \\
\text { knowledge score }>7 \\
\text { (median score) } \\
\text { significantly decreased } \\
\text { odds of LTBI (adjOR: } 0.29 \\
95 \% \text { Cl: } 0.09-0.98 \text { ) } \\
\text { Health care workers: no } \\
\text { significant association }\end{array}$ \\
\hline
\end{tabular}

In KwaZulu-Natal, Wilkinson et al. [21] reported that 12 out of the 14 TB cases in health care workers tested for HIV were positive. O'Donnell et al. [17] reported that of those tested, $67 \%$ of the health care workers admitted to hospital for MDR-TB or XDR-TB were HIVpositive. Tudor et al. [18] reported that $21 \%$ of the health care workers with TB were HIV-positive. In the Western Cape, Adams et al. [14] reported that 3/5 health care workers newly diagnosed with TB were HIVpositive.

\section{Diabetes}

There is limited data from the studies in this review on the association between diabetes and risk of TB disease or infection. Both of the nurses diagnosed with TB in Balt et al. had non-insulin dependent diabetes [26]. 
However, no significant association between diabetes and risk of TB disease or infection was noted in the two studies reporting on this relationship [20] (Adams: Prevalence and determinants of TB infection in health care workers, unpublished).

\section{TB infection prevention and control (IPC) training}

One study assessed the association between training in TB IPC and risk of active TB disease and found that health care workers who reported having had no previous TB IPC training were significantly more likely to acquire active TB disease (OR: 2.97, 95\%CI: 1.15-7.71) [20]. Two studies reported on the association between TB IPC knowledge, training and practice and the risk of incident latent TB infection [14, 22]. Adams et al. [14] found that having "some training in infection control procedures aimed at self-protection" significantly reduced the odds of latent TB infection (TST positivity) in health care workers at secondary level health care facilities $(\mathrm{OR}=0.38 ; 95 \% \mathrm{CI}:$ 0.17-0.87). Similarly, McCarthy et al. [22] found that a higher TB knowledge score (as measured by IGRA, crude IRR: 0.4, 95\%CI: 0.1, 1.3), TB infection control training (as measured by IGRA, crude IRR: $0.4,95 \%$ CI: 0.1, 1.2) and TB infection control practiced by participants (as measured by TST, crude IRR: $0.4,95 \%$ CI: $0.1,1.3)$ significantly reduced the risk of incident latent TB infection.

Van Rie et al. [23] found that medical students who had a TB knowledge score $>7$ (the median score for all participants), had reduced odds of a positive TST by $>70$ \% (adjusted OR: 0.29; 95 \% CI: 0.09-0.98).

\section{Discussion}

The majority of the studies reflect a high burden of active TB disease and latent TB infection in health care workers in South Africa. Although ten studies provide information on the incidence of active TB disease, only two studies provide information on the prevalence of active TB disease in health care workers in South Africa. Furthermore, only two studies reported on the incidence of latent TB infection with only three studies reporting on the prevalence of latent TB infection. Only two studies reported on the burden of specifically drug-resistant TB in South African health care workers. Most of the studies were conducted in the provinces of Kwa-Zulu Natal and the Western Cape, with little to no information on the burden of active TB disease or latent TB infection in health care workers employed in health care facilities in the Eastern Cape, the Free State, the Northern Cape and the North West province. Considering the importance of the issue it is surprising that there is relatively little research describing the actual burden of TB in health care workers in South Africa.
Other reviews have shown that the local prevalence of TB and HIV influences the risk and burden of active TB disease in health care workers in those localities [1-3]. The background incidence of active TB disease differs between provinces in South Africa, with the background incidence/prevalence of active TB disease in KwaZuluNatal being one of the highest in the country. This may explain why the incidence of active TB disease was consistently higher in health care workers compared to the community in Kwa-Zulu Natal province and not in the Western Cape province.

Previous reviews have shown that the infectiousness of the patient population and the level of care of the facility, influence the extent of TB transmission to health care workers [1-3]. Health care workers at primary care facilities and those working in the community may be more likely to be exposed to infectious, as yet undiagnosed, TB patients compared to health care workers at tertiary care facilities. The studies reporting on prevalence of active TB disease, conducted in the Western Cape at a similar time (2009/2010), support this in that active TB disease was more prevalent in community health workers (5\%) [6] compared to health care workers in primary and secondary health care facilities (1.4\%) (Adams: Prevalence and determinants of $\mathrm{TB}$ infection in health care workers, unpublished).

Two studies provide information on the incidence of latent TB infection in health care workers. In both cases the annual incidence of latent $\mathrm{TB}$ infection in these South African health care workers is three to four times higher than the incidence previously reported in health care workers in India, another high TB incidence setting $[14,27,28]$.

There is limited data on the various risk factors for acquisition of active TB disease or latent TB infection in health care workers in South Africa (Table 3). HIV status and training in TB infection, prevention and control were the only two factors for which there were consistent associations. While HIV-positivity was significantly associated with increased odds of acquiring active TB disease, it was not consistently associated with increased odds of acquiring latent $\mathrm{TB}$ infection. The treatment of HIV and latent TB infection in health care workers will need to be explored in future studies to understand the impact on the development of active TB disease in HIVinfected health care workers.

In four studies training in TB infection prevention and control was significantly associated with decreased odds of acquiring active TB disease [20] and latent TB infection $[14,22,23]$. This finding emphasizes the importance of on-going TB infection prevention and control training among all health care workers in the facility. Considering these findings and that all employees of the health care facility are at risk of acquiring TB it can be 
emphasized that all employees of the health care facility should receive training in TB infection, prevention and control.

Previous reviews reported that the specific work locations and occupational categories of health care workers are associated with a higher risk of acquiring TB disease [1-3]. The studies in our review that investigated these relationships showed somewhat similar findings. In one study there was no significant association between health care worker occupation and incidence of active TB disease, however, specific work locations (TB ward, paediatric ward and the outpatient department) were significantly associated with increased risk of acquiring active TB disease [18]. In the other studies certain occupational categories of health care workers appeared to have higher incidence of active TB disease, however, only one of the four studies reporting on this found the difference in incidence rates between the various occupational categories to be statistically significantly different [20]. Nevertheless, it was startling to see the high incidence of active TB disease in housekeeping staff, paramedical staff and hospital security staff $[16,20]$. Housekeeping and hospital security staffs, in particular, are unlikely to receive training in appropriate TB infection prevention and control, providing a possible explanation for the high burden of TB in these individuals.

\section{Conclusions}

There is relatively little research on the epidemiology of TB in health care workers in South Africa, despite the importance of the issue. Only two studies provided information on the annual incidence of latent TB infection in health care workers in South Africa. In addition to this, there is a dearth of information on the epidemiology of TB in health care workers from Eastern Cape, Free State, the Northern Cape and the North West provinces of South Africa. The lack of comprehensive information on the true burden of $\mathrm{TB}$ in health care workers will have implications on the implementation of preventive therapy policies.

To determine the true extent of the TB epidemic in health care workers in South Africa, screening for active TB disease (with identification of drug resistant TB strains) should be conducted in all health care facility employees, in all health care facilities on a regular basis. Future research should investigate the optimal approach, in terms of cost-effectiveness, feasibility, practicality and usefulness, to TB screening for active TB disease in health care workers in South Africa.

Finally, the evidence base shows a high burden of both active and latent TB in health care workers in South Africa, necessitating an urgent need to improve existing TB infection, prevention and control measures in South African health care facilities. Further to this training in $\mathrm{TB}$ infection, prevention and control be provided to all health care facility employees, including nonclinical staff.

\section{Additional file}

Additional file 1: Table S1. List of excluded studies with reasons for exclusion. (DOCX $86 \mathrm{~kb}$ )

\section{Abbreviations}

HCW, health care worker; IGRA, interferon-gamma release assays; IRR, incident rate ratio; $L T B I$, latent tuberculosis infection; MDR-TB, multi-drug resistant tuberculosis; OR, odds ratio; TB, tuberculosis; TST, tuberculin skin test; XDR-TB, extensively drug-resistant tuberculosis.

\section{Acknowledgements}

The World Health Organization (WHO) commissioned the EVISAT project in support of the South Africa National Department of Health. USAID and the Joint United Nation Programme on HIV/AIDS funded the EVISAT project. The Centre for Evidence-based Health Care (CEBHC), Desmond Tutu TB Centre (DTTC), and the Health Systems and Services Research (HSSR) Unit at Stellenbosch University managed the EVISAT project. We would like to acknowledge Vittoria Lutje for conducting the search for the review. We would also like to thank Martie van der Walt and Shahieda Adams for providing us with additional published and unpublished data on this topic. Carrie Tudor and Martie van der Walt provided valuable input as internal peer-reviewers of the bigger review.

\section{Funding}

The World Health Organization (WHO), USAID and the Joint United Nation Programme on HIV/AIDS funded the EVISAT project of which this review formed an integral part.

Availability of data and materials

The systematic review incorporated and collated data from previously conducted primary research that is clearly referenced in this published article [and its supplementary information files] under the Reference section.

\section{Authors' contributions}

LG wrote the review protocol, screened search results for eligible studies and extracted data from all 15 included articles and drafted the final review. SM and $\mathrm{KD}$ assisted with screening of search results and edited the final review. MO assisted with data extraction and edited the final review. SA provided unpublished research relevant to the review and assisted with the write up of the review. MVDW and SB provided valuable input into the various drafts of the review. All authors have read and approved the final manuscript.

\section{Competing interests}

The authors declare that they have no competing interests.

Consent for publication

Not applicable.

\section{Ethics approval and consent to participate}

The systematic review incorporates and collates data from previously conducted primary research; therefore, ethical approval was not required to conduct the systematic review.

\footnotetext{
Author details

${ }^{1}$ Center for Evidence-based Health Care, Stellenbosch University, Cape Town, South Africa. ${ }^{2}$ Unit of Infection Prevention and Control, Stellenbosch University, Cape Town, South Africa. ${ }^{3}$ Lung Infection and Immunity Unit, Division of Pulmonology and University of Cape Town Lung Institute, Department of Medicine, University of Cape Town, Cape Town, South Africa. ${ }^{4}$ Centre for Occupational and Environmental Health Research, University of Cape Town, Cape Town, South Africa. ${ }^{5}$ World Health Organisation, Pretoria, South Africa. ${ }^{6}$ Tuberculosis Research Platform, South African Medical Research Council, Pretoria, South Africa. ${ }^{7}$ Cape Town City Health Department, Cape Town, South Africa.
} 
Received: 2 December 2015 Accepted: 28 July 2016 Published online: 20 August 2016

\section{References}

1. Baussano I, Nunn P, Williams B, Pivetta E, Bugiani M, Scano F. Tuberculosis among health care workers. Emerg Infect Dis. 2011;17(3):488-94.

2. Joshi R, Reingold AL, Menzies D, Pai M. Tuberculosis among Health-Care Workers in Low- and Middle-Income Countries: A Systematic Review. PLoS Med. 2006;3(12):e494.

3. Menzies D, Joshi R, Pai M. Risk of tuberculosis infection and disease associated with work in healthcare settings. Int J Tuberc Lung Dis. 2007;11: 593-605.

4. South African Department of Labour (SA DoL). Compensation Fund. Annual Report March 2006. http://www.labour.gov.za/DOL/documents/ annual-reports/annual-report-pfma/2006/department-of-labour-annualreport-2006. 2006.

5. Malangu N, Legothoane A. Analysis of occupational infections among health care workers in Limpopo province of South Africa. Glob J Health Sci. 2013:5(1):44-51.

6. Kranzer K, Bekker LG, van Schaik N, Thebus L, Dawson M, Caldwell J, Hausler H, Grant R, Wood R. Community health care workers in South Africa are at increased risk for tuberculosis. S Afr Med J. 2010;100(4):224-6.

7. Connelly D, Veriava Y, Roberts S, Tsotetsi J, Jordan A, DeSilva E. Prevalence of HIV infection and median CD4 counts among healh care workers in South Africa. S Afr Med J. 2007;97(2):115-20.

8. Shisana O, Hall EJ, Maluleke R, Chauveau J, Schwabe C. HIV/AIDS prevalence among South African health workers. S Afr Med J. 2004;94(10):846-50.

9. World Health Organisation. Joint WHO/LO policy guidelines on improving health worker access to prevention, treatment and care services for HIV and TB. In. Geneva: World Health Organisation Organisation; 2010.

10. Adams S, Ehrlich R, Ismail N, Quail Z, Jeebhay MF. Occupational Health Challenges Facing the Department of Health: Protecting employees against tuberculosis and caring for former mineworkers with occupational health disease. In: Padarath A, English R, editors. South African Health Review 2012/13. Durban: Health Systems Trust; 2013.http://www.hst.org.za/publications/south-africanhealth-review-2012/13.

11. South African Department of Health. Human Resources for Health Strategy for the Health Sector: 2012/13-2016/17. In. Human Resources for Health South Africa; Pretoria;2011.

12. WHO. Health workers: a global profile. In. The world health report 2006: working together for health. Geneva: World Health Organisation; 2006.

13. Wells G, Shea B, O'Connell D, Peterson J, Welch V, Losos M, Tugwell P. The Newcastle-Ottawa Scale (NOS) for assessing the quality of nonrandomised studies in meta-analyses. 2013. http://www.ohri.ca/programs/clinical_ epidemiology/oxford.asp

14. Adams S, Ehrlich R, Baatjies R, van Zyl-Smit RN, Said-Hartley Q, Dawson R, Dheda K. Incidence of occupational latent tuberculosis infection in South African healthcare workers. Eur Respir J. 2015:45:1364-1373.

15. Claassens MM, van Schalkwyk C, du Toit E, Roest E, Lombard CJ, Enarson DA, Beyers N, Borgdorff MW. Tuberculosis in healthcare workers and infection control measures at primary healthcare facilities in South Africa. PLoS One. 2013;8(10):e76272.

16. Naidoo S, Jinabhai CC. TB in health care workers in KwaZulu-Natal, South Africa. Int J Tuberc Lung Dis. 2006;10(6):676-82.

17. O'Donnell MR, Jarand J, Loveday M, Padayatchi N, Zelnick J, Werner L, Naidoo K, Master I, Osburn G, Kvasnovsky C, et al. High incidence of hospital admissions with multidrug-resistant and extensively drug-resistant tuberculosis among South African health care workers. Ann Intern Med. 2010;153(8):516-22.

18. Tudor C, Van der Walt M, Margot B, Dorman SE, Pan WK, Yenokyan G, Farley JE. Tuberculosis among health care workers in KwaZulu-Natal, South Africa: a retrospective cohort analysis. BMC Public Health. 2014;14:891.

19. World Health Organisation. WHO Global TB Database. In. Geneva: World Health Organisation; http://www.who.int/tb/country/en/.

20. Ayuk J. A cross-sectional study of tuberculosis among workers in Tygerberg Academic Hospital, Western Cape province, South Africa. Stellenbosch University; 2012. http://hdl.handle.net/10019.1/85836. Accessed 3 Aug 2016.

21. Wilkinson D, Gilks CF. Increasing frequency of tuberculosis among staff in a South African district hospital: impact of the HIV epidemic on the supply side of health care. Trans R Soc Trop Med Hyg. 1998;92(5):500-2.
22. McCarthy KM, Scott LE, Gous N, Tellie M, Venter WD, Stevens WS, Van Rie A. High incidence of latent tuberculous infection among South African health workers: an urgent call for action. Int J Tuberc Lung Dis. 2015;19(6):647-53.

23. van Rie A, McCarthy K, Scott L, Dow A, Venter WD, Stevens WS. Prevalence, risk factors and risk perception of tuberculosis infection among medical students and healthcare workers in Johannesburg, South Africa. S Afr Med J. 2013;103(11):853-7.

24. Naidoo S, Mahommed A. Knowledge, attitudes, behaviour and prevalence of TB infection among dentists in the western Cape. SADJ. 2002;57(11):476-8.

25. Jarand J, Shean K, O'Donnell M, Loveday M, Kvasnovsky C, Van der Walt M, Adams S, Willcox P, O'Grady J, Zumla A, et al. Extensively drug-resistant tuberculosis (XDR-TB) among health care workers in South Africa. Trop Med Int Health. 2010;15(10):1179-84.

26. Balt E, Durrheim DN, Weyer K. Nosocomial transmission of tuberculosis to health care workers in Mpumalanga. S Afr Med J. 1998;88(11):1363-6.

27. Christopher DJ, James P, Daley P, Armstrong L, Isaac BT, Thangakunam B, Premkumar B, Zwerling A, Pai M. High annual risk of tuberculosis infection among nursing students in South India: a cohort study. PLoS One. 2011; 6(10):e26199.

28. Pai M, Joshi R, Dogra S, Mendiratta DK, Narang P, Kalantri S, Reingold AL, Colford Jr JM, Riley LW, Menzies D. Serial testing of health care workers for tuberculosis using interferon-gamma assay. Am J Respir Crit Care Med. 2006;174(3):349-55.

29. Mehtar S. Lowbury Lecture 2007: infection prevention and control strategies for tuberculosis in developing countries - lessons learnt from Africa. Journal of Hospital Infection. 2008:69(4):321-7.

\section{Submit your next manuscript to BioMed Central and we will help you at every step:}

- We accept pre-submission inquiries

- Our selector tool helps you to find the most relevant journal

- We provide round the clock customer support

- Convenient online submission

- Thorough peer review

- Inclusion in PubMed and all major indexing services

- Maximum visibility for your research

Submit your manuscript at www.biomedcentral.com/submit
) Biomed Central 